\title{
Note from the Editor-in-Chief
}

Besides a number of book reviews on a variety of topics, ranging from early China coast meteorology to stem cell governance in China, this issue of EASTM focuses on two major contributions, one jointly authored by Michela Bussotti and Han Qi, the other by Togo Tsukuhara. Bussotti and Han's article entitled "Typography for a Modern World? - The Ways of Chinese Movable Types" highlights some unknown facets of the history of printing in the Middle Kingdom. It makes clear that, though printing with moveable types did not constitute the mainstream approach, it nonetheless had a certain share in both official and private book production that varied according to place and time until the introduction of modern European typography during the nineteenth century. Even today some pockets survive in which Chinese traditional movable types continue to be used. In their richly documented and critical article, the authors conclude that while block printing was most suitable for recurring demands for small quantities over long periods of time, the method of movable type was more ideal for large, nonrecurring outputs. With regard to the latter, this especially held true for the printing of genealogies in Central and Southeast China, i.e. a genre containing often-used terms and characters. Moreover it can be stated with certainty that moveable types were in most cases made of wood, which therefore constituted the prime material for the printing matrices, regardless whether they were movable type or blocks and notwithstanding the famous use of bronze movable types for the printing of the Gujin tushu jicheng 古今圖書集成 (Collection of Texts and Illustrations of Ancient and Current Times), finished 1728.

The second article written by Togo Tsukahara deals with an unpublished manuscript of von Siebold (1796-1866), the Geologica Japonica, and especially highlights the development of geology, mineralogy and knowledge of copper in the context of Dutch colonial sciences and of the introduction of Western geo-sciences to Japan. The contribution is based on a newly found manuscript as well as a hitherto unknown collection of rocks and minerals from Japan, the latter having its provenance in the activities of Heinrich Burger (1806-1858), a pharmacist and assistant to von Siebold. Togo Tsukuhara concludes that the pan-European character of Dutch science was advantageous for the later development of modern science in Japan, as that country thus obtained knowledge from all over Europe. The network of knowledge involved in this transmission is characterized by the author as of an extensive nature, with various levels of different types of actors and multi-layered contacts. Moreover, it was hybrid, as, for instance, evidenced by the collaboration of indigenous collectors and a Western classificatory in the person of Burger. The beginnings of the rise 
of Japan as a modern industrial nation are attributed by the contributor to the trickling-down of Dutch scientific material, which took place, however, within a context of colonial sciences, and the hybrid formation between indigenous knowledge and Western colonial sciences.

At this point, let me preview forthcoming issues of EASTM, at least those that still will be edited under my direction. Issues 41 and 42 (2015) will be dedicated to the history of Chinese medicine. We are honoured to have Bridie J. Andrews as guest-editor, who will comment on four articles. After Prof. Andrew's introduction, no. 41 will start with TJ Hinrichs on the theoretization of Warmth disorders/diseases and Warmth epidemics (wenbing 溫病, wenyi 瘟疫) and its conceptual limits from the Han (206 BC$220 \mathrm{AD})$ to the Song period (960-1279), and Che-chia Chang providing a history of the Qing (1644-1911) Imperial Academy, the Taiyiyuan 太醫院. This will be continued in issue 42 with articles from Henrietta Harrison about the experience of illness in rural Shanxi during the early twentieth century, and be concluded with Bridie Andrews' contribution on Ding Fubao 丁福保 (1874-1952) and his project on modernizing medicine during the years from 1900 to 1927.

Issues 43 and 44 (2016) are likewise dedicted to a fine special issue, "Numerical Tables and Tabular Layouts in Chinese Scholarly Documents," directed and introduced by Karine Chemla. Articles include, in no. 43, those of Daniel Morgan (The Planetary Visibility Tables in the SecondCentury BC Manuscript $W u$ xing zhan 五星占), Michael Nylan (Mapping Time in the Shiji and Hanshu Tables), and Ma Biao (The Question of pangxing 旁行 and xieshang 邪上 in Shiji's 史記 Historical Tables), continued in no. 44 by Li Liang (Arabic Astronomical Tables in China: Tabular Layout and its Implications for the Transmission and Use of the Huihui lifa 回回曆 法) and Karine Chemla (Texts of Mathematical Tables in Chinese Manuscripts (preliminary title)).

As almost all the above-mentioned manuscripts are in our hands, we are confident that, thanks to the great efforts and generous support of the complete EASTM team, we will be able to publish them all in 2016, that is, before the journal will be handed over to the new Editor-in-chief Catherine Jami. At any rate, hand-over procedures have already started to ensure that the transition will be smooth.

Hans Ulrich Vogel

Eberhard Karls University of Tübingen

Institute of Asian and Oriental Studies

Department of Chinese and Korean Studies 